\title{
Rare case of fungal keratitis caused by Plectosporium tabacinum
}

This article was published in the following Dove Press journal:

Clinical Ophthalmology

4 October 2012

Number of times this article has been viewed

\section{Rika Kamada' \\ Yu Monden' \\ Koji Uehara' \\ Ryoji Yamakawa' \\ Kazuko Nishimura ${ }^{2}$ \\ 'Department of Ophthalmology, Kurume University School of Medicine, Kurume, Fukuoka, ${ }^{2}$ Medical Mycology Research Center, Chiba University and First Laboratories Co, Ltd, Kawasaki, Kanagawa, Japan}

Correspondence: Rika Kamada Department of Ophthalmology, Kurume University School of Medicine,

67 Asahi-machi, Kurume,

Fukuoka 830 00I I, Japan

Tel +8I 9423 I 7574

Fax +8I 942370324

Email yamashita_rika@med.kurume-u.ac.jp
Abstract: A rare case of fungal keratitis caused by Plectosporium tabacinum is reported. A 78-year-old female gardener presented with conjunctivitis and an oval infiltrate with irregular margins in the nasal half of the cornea in the right eye. Light microscopy of corneal scrapings revealed a filamentous fungus, and a diagnosis of fungal keratitis was made. The patient was admitted into our hospital on February 19, 2008. Treatment with topical miconazole, topical fluconazole, pimaricin ointment, intravenous miconazole, and corneal debridement was commenced. One week later, the infiltrate improved, but the central part of the infiltrate was still deep. Topical fluconazole was switched to topical voriconazole, and intravenous miconazole was switched to intravenous voriconazole. One month after admission, the causative organism was identified by morphology and molecular biological analysis as Plectosporium tabacinum. The corneal infiltrate resolved 3 months after admission. A stromal scar persisted for 3 months after the patient was discharged. This is the first detailed report of fungal keratitis caused by P. tabacinum. Voriconazole was effective in treating this refractory keratitis.

Keywords: fungal keratitis, Plectosporium tabacinum, voriconazole, filamentous fungi

\section{Introduction}

Filamentous fungi are the major etiologic agents of fungal keratitis, with Fusarium and Aspergillus species most frequently implicated as primary pathogens. ${ }^{1}$ Here we report a refractory case of fungal keratitis caused by Plectosporium tabacinum, a filamentous fungus found in soil. To our knowledge, there have been only two reports of human infection caused by this species, including one case of fungal keratitis in Hungary ${ }^{2}$ and one case of onychomycosis in Brazil. ${ }^{3}$

\section{Case report}

A 78-year-old female gardener presented to a local ophthalmologist in December 2007 complaining of blurred vision and a foreign body sensation in her right eye. Her local ophthalmologist treated her with topical antibiotics for corneal abrasion in the right eye. Two months later, treatment with topical corticosteroids was initiated because her symptoms remained unchanged. However, her blurred vision intensified. She was referred to our facility with a diagnosis of corneal ulcer on February 18, 2008. Her medical history was significant for hypertension. She denied a history of ocular trauma. She had undergone cataract surgery with intraocular lens implantation in both eyes in 2007. At initial presentation, her visual acuity was counting fingers in the right eye and 0.8 in the left eye. Intraocular pressure was not measured in 
the right eye, but was $9 \mathrm{mmHg}$ in the left eye. Slit-lamp examination of the right eye revealed conjunctival injection, an oval infiltrate with irregular margins in the nasal half of the cornea, $2+$ cells, keratic precipitates, and hypopyon in the anterior chamber (Figure 1A and B). Corneal opacity prevented visualization of the fundus in the right eye. Light microscopy of corneal scrapings taken from the right eye at the initial presentation showed uniformly septate hyphae. The patient was diagnosed as having keratitis caused by a filamentous fungus, and was admitted into our hospital on February 19, 2008. Treatment was initiated with topical miconazole $0.1 \%$ and fluconazole $0.1 \%$ hourly, pimaricin $1 \%$ ointment six times a day, intravenous miconazole $400 \mathrm{mg}$ a day, and corneal debridement every 3 days. One week later, the infiltrate improved, but the central part of the infiltrate was still deep (Figure 1C). Topical fluconazole $0.1 \%$ was switched to topical voriconazole $1 \%$ hourly, and intravenous miconazole was switched to intravenous voriconazole $400 \mathrm{mg}$ daily. Microscopic examination of corneal scrapings cultured on potato dextrose agar and stained with lactophenol cotton blue did not identify any specific pathogen. One month after admission, the causative organism was identified as $P$. tabacinum, based on its morphology and the sequence of the internal transcribed spacer (ITS1-5.8S-ITS2) region of the ribosomal RNA gene. Drug susceptibility testing showed that the $80 \%$ inhibitory concentration $\left(\mathrm{IC}_{80}\right)$ of voriconazole against this organism was $0.125 \mu \mathrm{g} / \mathrm{mL}$, with good susceptibility (Table 1). Treatment with voriconazole
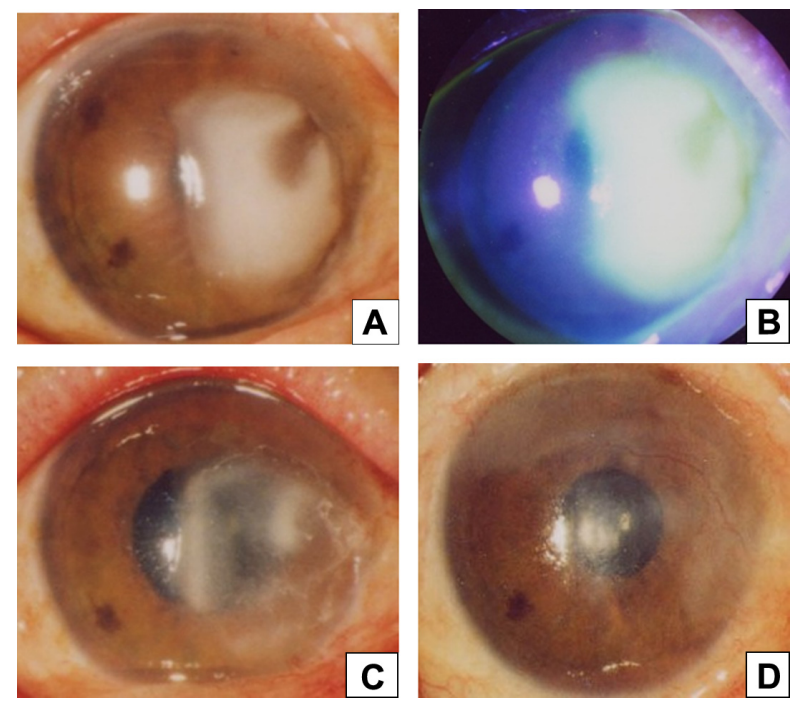

Figure I Slit-lamp photographs. (A) Oval infiltrate with irregular margins in the nasal half of the cornea at initial presentation. (B) Fluorescein staining at initial presentation. The lesion was not stained with fluorescein. (C) One week after admission, the infiltrate improved, but in the central part was still deep. (D) A stromal scar remained 3 months after the patient was discharged.
Table I Sensitivity of the isolate to various antifungal agents

\begin{tabular}{ll}
\hline Medicine & IC80 $(\mu \mathrm{g} / \mathrm{mL})$ \\
\hline Amphotericin B & $0.5^{*}$ \\
Flucytosine & $>64$ \\
Fluconazole & 64 \\
Itraconazole & 0.25 \\
Miconazole & $\mathrm{I}$ \\
Micafangin & 0.25 \\
Voriconazole & 0.125
\end{tabular}

Note: $* 100 \%$ inhibitory concentration.

Abbreviation: IC $80,80 \%$ inhibitory concentration.

was continued, and the infiltrate gradually reduced in size. However, due to the slow regression of the infiltrate, oral itraconazole $200 \mathrm{mg}$ a day was added to the treatment 2 months after admission. The $\mathrm{IC}_{80}$ of itraconazole was $0.25 \mu \mathrm{g} / \mathrm{mL}$. Liver function was evaluated regularly during administration of systemic voriconazole and itraconazole. Three months after admission, the corneal infiltrate resolved, and the patient was discharged. At the time of discharge, her right visual acuity was counting fingers, and intraocular pressure was $9 \mathrm{mmHg}$. Topical and systemic treatment with antifungal agents was continued after discharge. A stromal scar persisted for 3 months after discharge, and visual acuity was 0.02 (Figure 1D). The treatment course in the right eye is shown in Figure 2.

\section{Identification of causative organism}

The causative agent was initially searched for at the Central Clinical Laboratory of Kurume University Hospital but could not be identified. The isolate was then sent to First Laboratories Co, Ltd, where it was re-examined morphologically and analyzed using molecular biology techniques. The fungus produced dull salmon-pink, flat and smooth colonies, with fine aerial hyphae at the marginal area, after culture on potato dextrose agar at $25^{\circ} \mathrm{C}$ in the dark for 13 days (Figure $3 \mathrm{~A}$ ). Slide culture preparations showed conidiophores that were hyaline and hypha-like, unbranched or branched, and forming a scanty cluster (Figure 3B). Conidiogenous cells were phialides occurring on the tips of conidiophores or as side branches of hyphae. These were hyaline, hypha-like, and tapered toward the tops, with an open end and collarette (Figure 3B and $\mathrm{C}$, arrows). Phialides were straight or occasionally twisted (Figure 3B and D, asterisks). Phialoconidia formed in masses from the open ends. These were hyaline, cylindrical, pointed at both ends, straight or slightly curved at the basal portion, with 0-3 septa (mostly uniseptate), and were 7.0-12.9 × 1.8-3.6 $\mu \mathrm{m}$ (average $10.0 \times 2.6 \mu \mathrm{m}$ ) in size. Based on these morphological characteristics, the isolate was identified as P. tabacinum. ${ }^{4}$ 


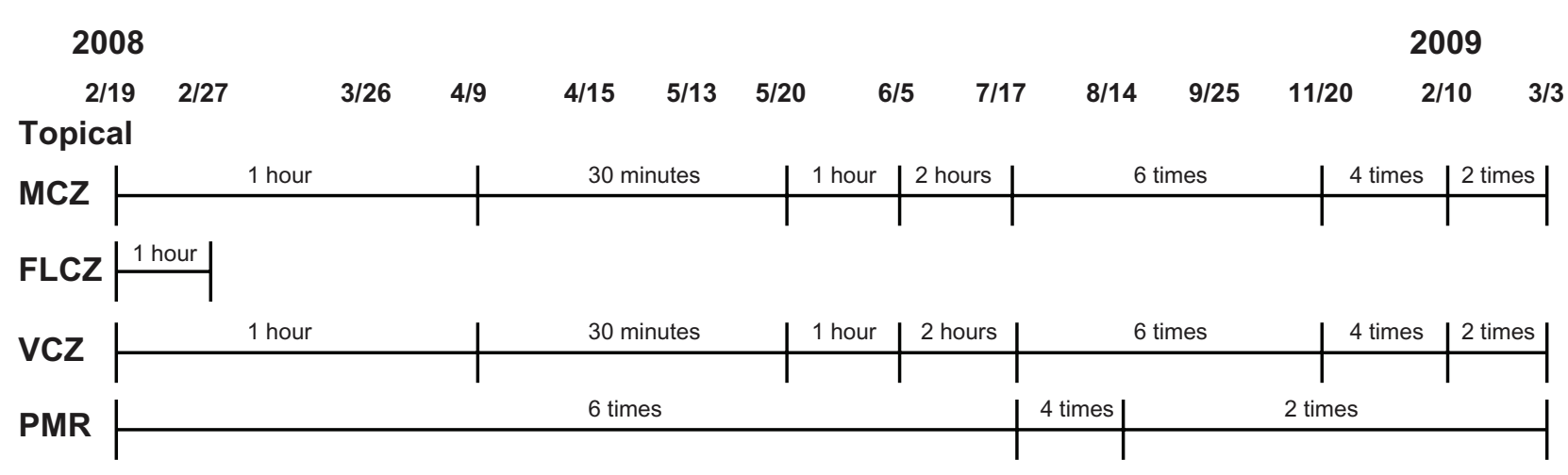

\section{Intravenous}

MCZ

VCZ

ITZ

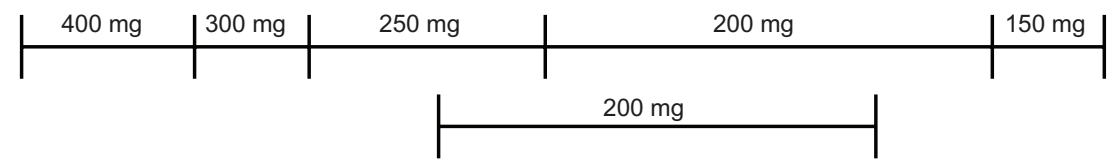

Figure 2 Treatment course for the right eye.

Abbreviations: MCZ, miconazole; FLCZ, fluconazole; VCZ, voriconazole; PMR, pimaricin; ITZ, itraconazole.

A Basic Local Alignment Search Tool (BLAST) search showed that the sequence on the ITS region had 100\% similarity with six sequences (AM408781, AB264787, AB264786, AB264782, AB266251, AB264785) on the ITS regions of Plectosphaerella cucumerina (the teleomorphic name of $P$. tabacinum) registered with the National Center for Biotechnology Information, National Institutes of Health, Bethesda, MD. This confirmed the morphological identification. The sequence was registered at the DNA Data Bank of Japan, National Institute of Genetics, Japan,
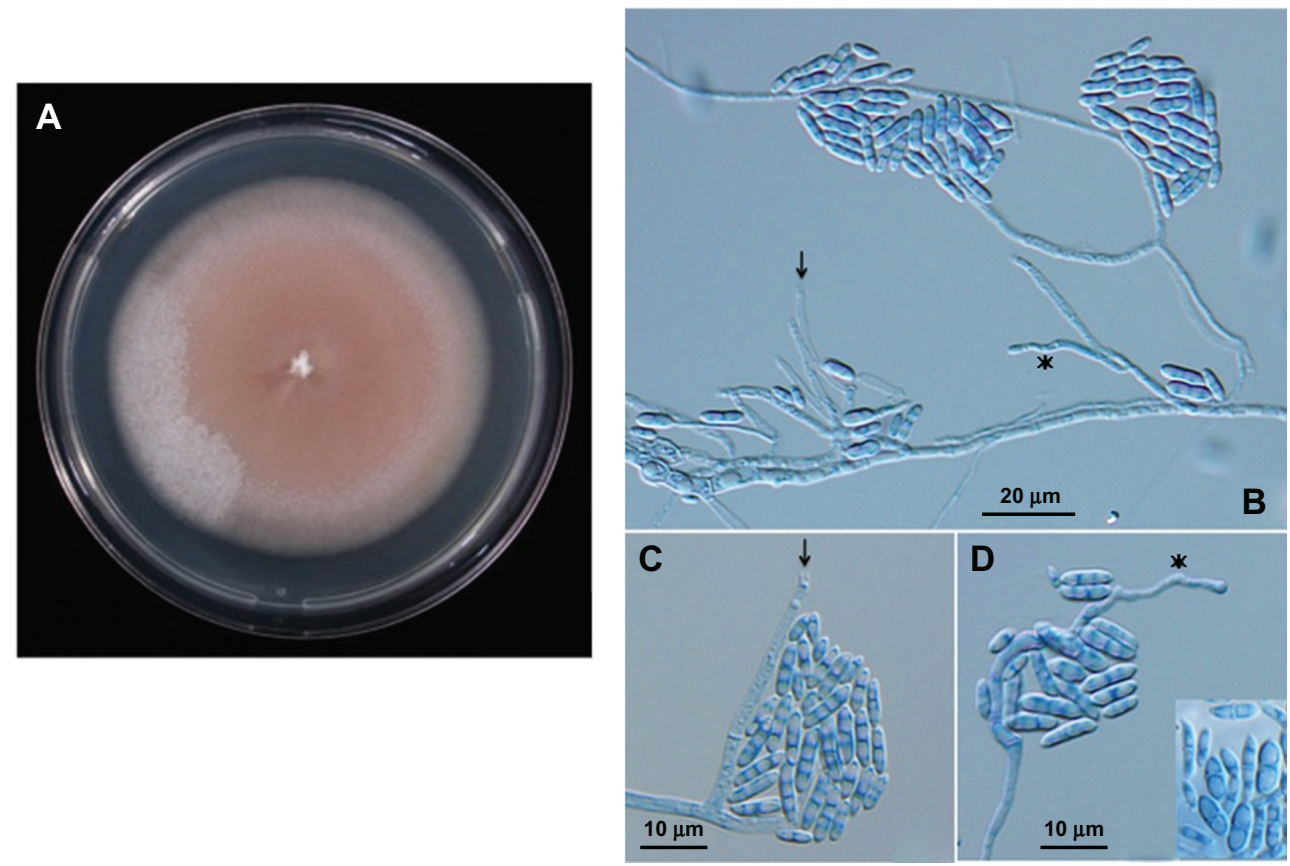

Figure 3 Morphological findings of the isolate. (A) Colony incubated on potato dextrose agar at $25^{\circ} \mathrm{C}$ for 13 days. (B, C, D) Microscopic findings on slide cultures grown on potato dextrose agar. Phialides arise from conidiophore apices or hyphae as side branches. They are straight or twisted (asterisks), tapering toward the tops, with an open end and collarette (arrows). Phialoconidia are cylindrical with pointed ends, or narrow spindle-shaped, straight, or slightly curved, and mostly uniseptate. Lactophenol cotton blue stain. $(B) \times 400$; $($ C and $D)$, and inset $\times 600$. 
as accession number AB469880, and a living culture was deposited at the Medical Mycology Research Center (originally the Institute for Food Microbiology), Chiba University, Japan, as IFM 58012.

\section{Discussion}

P. tabacinum is a soil-borne fungus and a saprophyte commonly found in decaying plants. It is ubiquitously found in soil throughout the world and is also known as a plant pathogen. A number of plant diseases, including diseases of sunflower and basil, have been reported. ${ }^{5}$ Some strains cause blight or spot diseases in vegetables and flowers in Japan. ${ }^{4}$ Interestingly, the ITS sequence of the isolate from our patient was $100 \%$ identical with those from some vegetables.

According to Palm et al, ${ }^{5}$ the teleomorph (sexual form) of $P$. tabacinum was first isolated from cucumber in 1919 and was named Venturia cucumeria by Lindfors. In 1933, the anamorph (asexual form) was isolated from diseased tobacco and was designated as Cephalosporium tabacinum. In 1968, the anamorph was later placed within the genus Fusarium and was then transferred in 1984 to the genus Microdochium, based on the morphology of the conidium. However, the characteristics of the conidia and the manner of conidiogenesis differ from those of Microdochium species, where conidia are blastic rather than phialidic. The name Plectosporium tabacinum was established by Palm et al in 1995, and has since been widely accepted.

P. tabacinum is a rare human pathogen. To our knowledge, only two cases have been reported, including one of fungal keratitis ${ }^{2}$ and one of onychomycosis. ${ }^{3}$ The previous report of fungal keratitis came from Hungary, and was presented in abstract form at the 14th International Society for Human and Animal Mycology World Congress, Buenos Aires, Argentina, in 2000. According to this abstract, a 57-year-old man had developed a corneal ulcer after grass struck his eye while he was weeding. Despite the lack of a pronounced inflammatory reaction, the clinical picture was highly suggestive of a fungal etiology. Corneal scrapings stained with Gomori-Grocott methenamine silver and Periodic acid Schiff showed fungal elements. Cultures on Sabouraud glucose agar yielded mold colonies. The fungus was identified as P. tabacinum at the Centraalbureau voor Schimmelcultures in The Netherlands.

In our case, it took about one month after obtaining samples from the lesion to identify the pathogen as P. tabacinum. Cultures on potato dextrose agar produced creamy, moist colonies measuring 40-50 mm in diameter after 12 days. Light microscopy with lactophenol cotton blue staining revealed regular septate hyphae with phialides that produced conidia. We initially suspected Fusarium as a pathogen, because this species is commonly isolated from fungal keratitis. ${ }^{1}$ However, cultures from the corneal scrapings did not show the crescent-shaped macroconidia characteristic of Fusarium species. Cultures were continued, and uniseptate conidia were produced. Because the causative agent could not be identified at our facility, the fungus was sent to First Laboratories Co, Ltd, for identification. It was re-examined morphologically, analyzed with molecular biology techniques, and confirmed as P. tabacinum. A diagnosis was made of fungal keratitis caused by this fungus.

P. tabacinum is a ubiquitous fungus found in soil and plants, but rarely causes human infection. The patient in the report of Simon et al, who underwent eye trauma while weeding, ${ }^{2}$ was a keen gardener, as was our patient. Both cases might have been infected with $P$. tabacinum through soil or agricultural products.

Theoulakis et $\mathrm{al}^{6}$ reported keratitis caused by a rare human pathogen, Thielavia subthermophilia. This fungus is also ubiquitously found in soil and plants, and the patient had corneal trauma inflicted from contact with a palm tree. In cases of fungal keratitis caused by rare human pathogens, the pathogen is often difficult to detect. We verified the morphological identification of our pathogen by DNA analysis. The pathogen in the case of Simon et al was identified as P. tabacinum at the Centraalbureau voor Schimmelcultures, which maintains a world-renowned collection of fungi, but the method of fungal identification was not described in the abstract. The fungus in the case of Theoulakis et al was also identified by a DNA sequence analysis with a BLAST search. Therefore, the ITS sequence analysis is useful for identification or confirmation of uncommon fungal pathogens.

Drug susceptibility testing in our case showed low susceptibility to fluconazole and miconazole, but high susceptibility to voriconazole. Voriconazole, a triazole antifungal agent, has excellent intraocular penetration. Hariprasad et $\mathrm{al}^{7}$ reported that the aqueous concentration of voriconazole was $1.13 \mu \mathrm{g} / \mathrm{mL}$ and the vitreous concentration was $0.81 \mu \mathrm{g} / \mathrm{mL}$ when the plasma concentration was $2.13 \mu \mathrm{g} / \mathrm{mL}$. The $\mathrm{IC}_{80}$ of voriconazole against $P$. tabacinum was $0.125 \mu \mathrm{g} / \mathrm{mL}$. The plasma voriconazole concentration of our patient was at least $2.16 \mu \mathrm{g} / \mathrm{mL}$ at all points in time during admission. Therefore, the aqueous voriconazole concentration of our patient was considered to be adequate. The infiltrate gradually reduced in size after initiation of voriconazole treatment. However, due to slow regression of 
the infiltrate, oral itraconazole was added to the treatment 2 months after admission. The organism showed relatively good susceptibility to itraconazole and the infiltrate improved.

Although fungal keratitis caused by this organism is extremely rare, the finding that this organism is sensitive to treatment with voriconazole but unresponsive to treatment with fluconazole and miconazole should be kept in mind. We initially treated our patient with fluconazole and miconazole, but the infiltrate did not respond well. Fungal keratitis reported by Simon et al was also treated with fluconazole and miconazole, but the keratitis was unresponsive to this treatment. ${ }^{2}$ The $\mathrm{IC}_{80}$ of itraconazole against $P$. tabacinum in our case was second only to that of voriconazole (Table 1). Thus, itraconazole may also be effective in the treatment of $P$. tabacinum keratitis. The choice of antifungal agents is important in the treatment of refractory fungal keratitis caused by $P$. tabacinum.

This is the first detailed report of $P$. tabacinum keratitis. Prompt and effective antifungal treatment is important in patients with refractory fungal keratitis. Sequencing of the ITS region is useful for fungal identification in patients with keratitis caused by a rare human pathogen.

\section{Acknowledgment}

We are deeply grateful to Dr Toyozo Sato, National Institute of Agrobiological Sciences, Ministry of Agriculture, Forestry and Fisheries, Japan, for his advice on the causative fungus.

\section{Disclosure}

The authors have no financial interests to report in this work.

\section{References}

1. Srinivasan M. Fungal keratitis. Curr Opin Ophthalmol. 2004;15(4): 321-327.

2. Simon G, Toth J, Torok I, et al. Fungal keratitis caused by Plectosporium tabacinum: first reported case. Abstract presented at the 14th International Society for Human and Animal Mycology World Congress. Buenos Aires, Argentina, May 8-12, 2000

3. Guilhermetti E, Takahachi G, Cristiane S, et al. Fusarium spp. as agents of onychomycosis in immunocompetent hosts. Int J Dermatol. 2007; 46(8):822-826.

4. Sato T, Inaba T, Mori M, Watanabe K, Tomioka K, Hamaya E. Plectosporium blight of pumpkin and ranunculus caused by Plectosporium tabacinum. J Gen Plant Pathol. 2005;71(2):127-132.

5. Palm ME, Gams W, Nirenberg HI. Plectosporium, a new genus for Fusarium tabacinum, the anamorph of Plectosphaerella cucumerina. Mycologia. 1995;87(3):397-406.

6. Theoulakis P, Goldblum D, Zimmerli S, et al. Keratitis resulting from Thielavia subthermophilia Mouchacca. Cornea. 2009;28(9): 1067-1069.

7. Hariprasad SM, Mieler WF, Holz ER, et al. Determination of vitreous, aqueous, and plasma concentration of orally administered voriconazole in humans. Arch Ophthalmol. 2004;122(1):42-47.
Clinical Ophthalmology

\section{Publish your work in this journal}

Clinical Ophthalmology is an international, peer-reviewed journal covering all subspecialties within ophthalmology. Key topics include: Optometry; Visual science; Pharmacology and drug therapy in eye diseases; Basic Sciences; Primary and Secondary eye care; Patient Safety and Quality of Care Improvements. This journal is indexed on

\section{Dovepress}

PubMed Central and CAS, and is the official journal of The Society of Clinical Ophthalmology (SCO). The manuscript management system is completely online and includes a very quick and fair peer-review system, which is all easy to use. Visit http://www.dovepress.com/ testimonials.php to read real quotes from published authors. 